\title{
Commentary: Filling the gap: Can ventricular assist devices support hearts with a single ventricle?
}

\author{
Emilie Jean-St-Michel, MDCM, FRCPC, MSc, Mjaye Mazwi, MBCHB, and Aamir Jeewa, MD, FRCPC
}

\author{
From the Division of Cardiology, Labatt Heart Center, The Hospital for Sick Children, University of Toronto, Tor- \\ onto, Ontario, Canada. \\ Disclosures: Authors have nothing to disclose with regard to commercial support. \\ Received for publication April 24, 2019; accepted for publication April 25, 2019; available ahead of print June 10, \\ 2019. \\ Address for reprints: Aamir Jeewa, MD, FRCPC, Division of Cardiology, Labatt Heart Center, The Hospital for \\ Sick Children, 555 University Ave, Toronto, Ontario, Canada M5G 1X8 (E-mail: aamir.jeewa@sickkids.ca). \\ J Thorac Cardiovasc Surg 2019;158:63-4 \\ $0022-5223 / \$ 36.00$ \\ Copyright (c) 2019 by The American Association for Thoracic Surgery \\ https://doi.org/10.1016/j.jtcvs.2019.04.069
}

Philip and colleagues ${ }^{1}$ report the successful experience of bridging an infant with hypoplastic left heart syndrome to heart transplantation using an Excor ventricular assist device (VAD) (Berlin Heart Inc, The Woodlands, Tex). ${ }^{1}$ The authors describe an innovative strategy for supporting failing stage 1 single ventricle physiology in small patients (2.5-3.75 kg). Innovations include the choice of a pulsatile pump, the use of bivalirudin for anticoagulation, pulmonary artery banding, and atrial cannulation. Although the use of VADs in pediatrics has been associated with a $50 \%$ reduction in waitlist mortality, congenital heart disease (CHD) and small patient size remain strong risk factors for waitlist mortality. ${ }^{2}$ Infants with single ventricle (SV) physiology pose additional anatomic and physiologic challenges when considering mechanical circulatory support due to the need to balance cardiac output to the pulmonary and systemic circulations. A previous analysis described poor outcomes for small infants supported with the Excor and particularly poor survival in those weighing $<5 \mathrm{~kg} .{ }^{3}$ Despite small size/weight and SV physiology, complication-free support is feasible with some innovation.

Recent analysis of the Pediatric Interagency Registry for Mechanical Circulatory Support demonstrated that patients with CHD continue to have higher mortality than patients without CHD on VAD support, but SV physiology did not seem to further influence outcomes. ${ }^{4}$ The authors believe that this observation supports ongoing innovations like that described by Philip and colleagues ${ }^{1}$ to support patients with SV physiology with bridging strategies.

There are no consensus guidelines on how to manage patients with SV physiology on a VAD. Even the choice of pump varies between centers. In a study by Peng and colleagues, ${ }^{4} 78 \%$ of patients with SV physiology after stage 1 palliation were supported with a paracorporeal continuous flow pump that appeared to be associated with improved survival in those patients. The atrial cannulation approach used in this patient - and previously described by Ma and colleagues $^{5}$ for patients with a smaller ventricular and efficacy. ${ }^{6,7}$

\section{References}

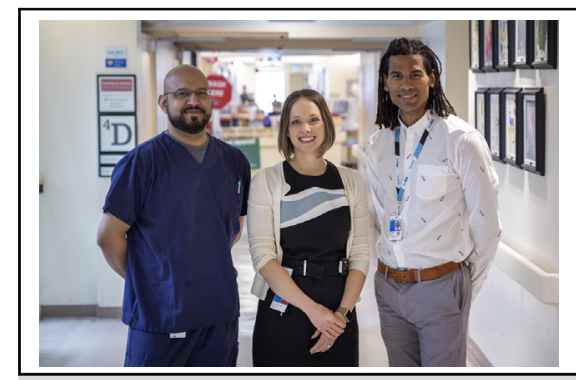

Aamir Jeewa, MD, FRCPC, Emilie Jean-St-Michel, MDCM, FRCPC, MSc, and Mjaye Mazwi, MBCHB

\section{Central Message}

Novel management strategies for pediatric patients with a VAD might be safely expanding the VAD support strategies for infants with complex congenital heart disease.

See Article page e59.

cavity-is an example of an innovative strategy that may have augmented the device's ability to provide balanced cardiac output with a pulsatile pump in the context of a systemic right ventricle. In addition, anticoagulation management is evolving with direct thrombin inhibitors gaining popularity based on limited but positive reports of safety

Philip and colleagues ${ }^{1}$ identify this strategy as part of a successful program at their institution aimed at supporting failing small patients with SV physiology to transplant or decision with acceptable outcomes in the current era. We encourage them to expand this experience with VADs after stage 1 palliation for SV physiology and hope the wider community is emboldened to pursue larger-scale collaborations directed at making extracorporeal support a more consistent option for this high-risk group.

1. Philip J, Reyes K, Ebraheem M, Gupta D, Fudge JC, Bleiweis MS. Hybrid procedure with pulsatile ventricular assist device for hypoplastic left heart syndrome awaiting transplantation. J Thorac Cardiovasc Surg. 2019;158:e59-61.

2. Zafar F, Castleberry C, Khan MS, Mehta V, Bryant R III, Lorts A, et al. Pediatric heart transplant waiting list mortality in the era of ventricular assist devices. $J$ Heart Lung Transplant. 2015;34:82-8.

3. Conway J, St Louis J, Morales DL, Law S, Tjossem C, Humpl T. Delineating survival outcomes in children $<10 \mathrm{~kg}$ bridged to transplant or recovery with the Berlin Heart EXCOR ventricular assist device. JACC Heart Fail. 2015;3:70-7.

4. Peng DM, Koehl DA, Cantor RS, McMillan KN, Barnes AP, McConnell PI et al. Outcomes of children with congenital heart disease implanted with 
ventricular assist devices: an analysis of the pediatric interagency registry for mechanical circulatory support (Pedimacs). J Heart Lung Transplant. 2019;38: 420-30.

5. Ma M, Yarlagadda VV, Rosenthal DN, Maeda K. A novel inflow cannulation strategy for pediatric mechanical circulatory support in small left ventricles. J Thorac Cardiovasc Surg. 2017;154:e47-8.
6. Rutledge JM, Chakravarti S, Massicotte MP, Buchholz H, Ross DB, Joashi U. Antithrombotic strategies in children receiving long-term Berlin Heart EXCOR ventricular assist device therapy. J Heart Lung Transplant. 2013;32:569-73.

7. Pieri M, Agracheva N, Di Prima AL, Nisi T, De Bonis M, Isella F, et al. Primary anticoagulation with bivalirudin for patients with implantable ventricular assist devices. Artif Organs. 2014;38:342-6. 